\title{
Moisture decay in buildings and the impact of weather
}

\author{
Valeria Cascione $^{* a}$, Daniel Maskell ${ }^{\mathrm{a}}$, Andy Shea ${ }^{\mathrm{a}}$, Pete Walker ${ }^{\mathrm{a}}$ \\ a Department of Architecture and Civil Engineering, University of Bath, Bath, UK
}

\begin{abstract}
Moisture levels inside buildings are influenced by many factors, including ventilation levels, daily weather conditions, seasonal climates, and material hygroscopicity. It is complex to discern the contribution of these factors in regulating moisture levels, and to quantify the capacity of hygroscopic materials applied on internal surfaces to moderate the indoor humidity, a process referred as moisture buffering. In this study, full-scale experimentation was performed on two single room test buildings (cells) to evaluate the role of moisture buffering at large scale. A statistical model was developed to extrapolate the impact of weather on the indoor moisture balance and to investigate the influence of hygroscopic materials in the room relative humidity. This is a first step into the quantification of the moisture buffering capacity of walls in buildings.

In Peer-review under the responsibility of the organizing committee of the ICMB21.
\end{abstract}

Keywords: moisture decay, indoor moisture

\section{Introduction/Background}

There are multiple parameters to consider when considering the moisture balance in buildings, including infiltration, ventilation, moisture buffering and weather conditions [1]. As Kraniotis et al. [2] demonstrated, moisture buffering is influenced by air leakages, as help finishing materials to dry faster. However, moisture transport through infiltration depends on the variable outdoor weather conditions. Yoshino et al [3] highlighted the inverse correlation between ventilation rates and sorption capacity. Ventilation influences the moisture exchange that, depending on the weather, adds and removes moisture from the indoors. Consequently, the outdoor environment strongly influences the indoor environment [4].

In this paper, a large-scale experimental study on the impact of weather variations on indoor moisture level was performed. A full-scale test cell was compared to a non-hygroscopic cell (reference cell). A statistical model was developed to quantify the effect of the weather in the indoor environment and to isolate the impact of moisture buffering in the cells.

\section{Case study and methodology}

Two test rooms, located at the University of Bath's Building Research Park in Wiltshire, were tested. The test cells external dimension is $4.34 \mathrm{~m} \times 4.34 \mathrm{~m} \times 2.94 \mathrm{~m}$ high; the internal dimensions are defined by wall thicknesses, which differ for each room to provide a consistent designed U-value of $0.15 \mathrm{~W} / \mathrm{m}^{2} \mathrm{~K}$. The reference room is a PIR insulated timber frame building, whilst the hygroscopic cell is a concrete cavity wall with PIR insulation. Floors, ceilings, and doors were covered with an impermeable layer, to exclude these components from the room moisture buffering.

Both cells use gypsum plasterboard on the indoor surface, but the reference cell was entirely covered by an impermeable sheet $(\mathrm{sd}=4000 \mathrm{~m}$ ), to prevent any moisture buffering. A gas decay test indicated cells showed similar measured infiltration rate $(0.06 \mathrm{ACH})$. Indoor and outdoor temperature, $\mathrm{RH}$ and wind were monitored. The indoor temperature was kept at $23^{\circ} \mathrm{C}$, whilst a humidifier regulated the moisture content in the cells. The test consisted of 8 hours of high humidity (75\%RH) followed by 40 hours of moisture decay. During the moisture decay, the moisture reduction was observed until the humidity level returned to the initial RH before testing. The test was repeated seven times.

\section{Results, Analysis and Discussion}

In this paper the impact of weather on the moisture decay was investigated. As shown in Fig.1a, the hygrscopic room reduced faster the moisture content in the room. This is due to the plaster that keeps storing moisture into the wall, to reduce the peak of $\mathrm{RH}$ generated during the humidification, as it did not reach the saturation during the humidification ( $\mathrm{RH}<75 \%)$. Moreover, in the reference cell the average moisture decay response curve flattened from the $12^{\text {th }}$ hour after the end of the humidification, whilst the hygroscopic cell presented more steady and smooth decay, probably due to the plasterboard participation in

\footnotetext{
* Corresponding author. V.cascione@bath.ac.uk
} 


\section{ICMB21}

moderating the indoor environment. A statistical analysis was performed to quantify the impact of the outdoor weather on the indoor humidity and to, successively, standardize the curves, by accounting for the effect of the weather. A repeated measurements mixed model was applied. In the analysis the outdoor weather was considered identical for both rooms. The statistical structure chosen for the model was auto-regressive, due to the dependency of each data point with the previous point. The absolute humidity both for the indoor and outdoor was considered instead of RH, to eliminate the dependency of RH on the temperature. The effect of the outdoor temperature, absolute humidity, wind speed and time (fixed effects) on the indoor absolute humidity was analysed, whilst comparing the two room's performances. Introduction of time as a variable and as an influencing factor was a way to consider unpredictable variables. For example, time represents the simultaneous impact on the rooms of the outdoor factors and variations in the materials performances over time, like the walls absorbing less water, due to saturation, or water infiltrating through the impermeable layer or seals.

The results of the statistical analysis showed that all the outdoor factors influenced the indoor absolute humidity. The outdoor absolute humidity decreased the indoor humidity level, while wind speed and temperature increased it. Every hour the absolute humidity decreased by $0.13 \mathrm{~g} / \mathrm{m}^{3}$, whilst variations of the temperature and wind speed raised the indoor moisture content by $0.063 \mathrm{~g} / \mathrm{m}^{3}$. Temperature and wind speed impact was significantly lower than humidity and time. The squared and cubic value of the time and multiplied values (weather by time) were introduced as they represent the curvature of the decay. The multiplied values did not impact the indoor moisture level but did impact the steepness of the decay.

The statistical analysis also indicated that there were no significant differences between the cells in terms of moisture content reduction at the end of the observation period (Fig.1b). As the rooms presented similar absolute humidity levels, the walls have little impact on the overall humidity decay, but infiltration is playing a much more important role in the decay. The doors were unlikely to be as moisture tight as the other components of the building and consequently moisture migrated through it. Even though the cells reached the same humidity level at the end of the 40 hours $\left(10 \mathrm{~g} / \mathrm{m}^{3}\right)$, the differences in the curvature of the moisture decay, either in the predicted and measured cases, indicated the hygroscopic cell smoothed and accelerated the decay, by eliminating humidity fluctuation produced by the outdoor weather, while the reference cell was more sensitive to outdoor environmental variations.
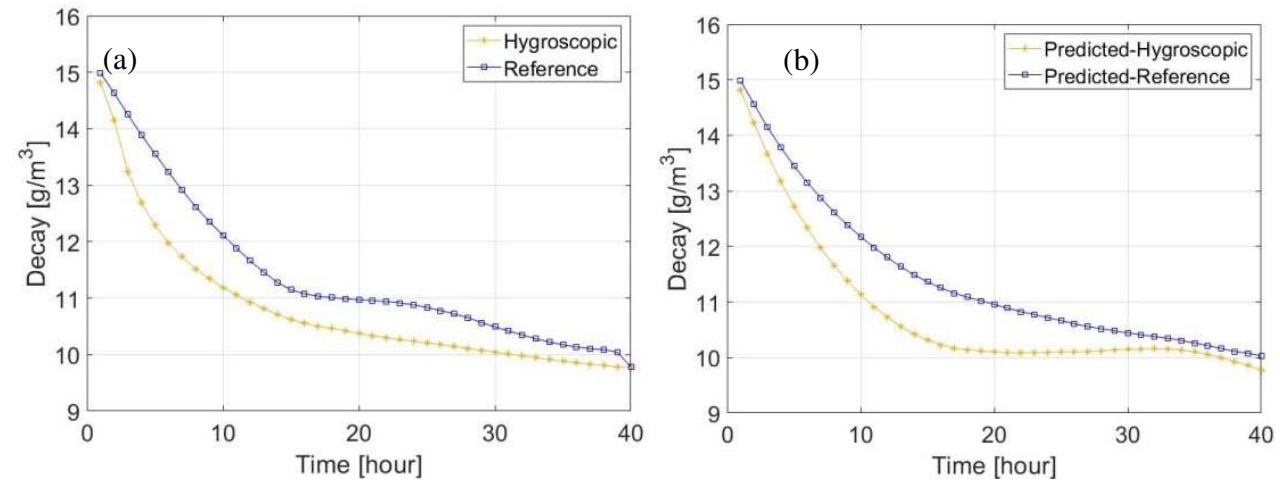

Figure 1. Average moisture decay in the hygroscopic and reference cell (a); predicted decay (b)

\section{Conclusions}

The moisture decay in experimental test cells showed that the moisture reduction followed a logarithmic curve in all rooms. The decay did not present significant differences, as at the end of the test both cells reached the same RH, and the statistical analysis demonstrated the cells were similarly impacted by the outdoor temperature, RH and air speed. However, the rate of change and speed of the decay curve was significantly different in the two rooms. Overall, the analysis highlighted moist air was removed mainly through infiltration, while the walls smoothed the decay and reduced the indoor humidity fluctuations caused by the weather. This research indicated that the cells activated different mechanism to dissipate similar amount of moisture, but it also demonstrated hygroscopic walls not only buffer moisture, but also mitigate moisture transaction between high and low humidity.

\section{References}

[1] Cascione V., Maskell, D. Shea, A., Walker, P. and Mani, M. (2020). Comparison of moisture buffering properties of plasters in full-sclae simulations and laboratyory. Construction and Building Materials, 252, 119033.

[2] Kraniotis, D., Aurlien, T., Bruckner, C. and Nore, K. (2015). Impact of air infiltration rates on moisture buffering effect of wooden surfaces. Proceedings: $36^{\text {th }}$ air infiltration ventilation conference $-5^{\text {th }}$ tighvent- $3^{\text {rd }}$ venticool, Madrid, Spain. pp 23-24.

[3] Yoshino, H. Mitamura, T. and Hasegawa, K. (2009). Moisture buffering and effect of ventilation rate and volume rate of hygrothermal materials in a single room under steady state exterior conditions. Buildings and environment, 44(7), pp1418-1425.

[4] Nguyen, J.L, Schwartz, J. and Dockery, D.W. (2014). The relationship between indoor and outdoor, temperatyre, apparent temperature, relative humidity and apparent humidity. Indoor Air, 24(1), pp 103-112. 